\title{
Novas fronteiras tecnológicas das ações de informação: questões e abordagens
}

\author{
Maria Nélida González de Gómez \\ Doutora em Comunicação. Pesquisadora titular \\ Ibict-MCT. \\ E-mail: maria.nelida@terra.com.br
}

\section{Resumo}

Mudanças significativas dos conceitos e abordagens acerca da informação e da comunicação acontecem ao mesmo tempo em que muda a relação entre os usos da linguagem e as mediações tecnológicas desses usos - ainda que não seja de forma causal. O mesmo aconteceria com a reformulação dos dispositivos de informação pela crescente convergência entre as tecnologias culturais e de reprodução e as tecnologias digitais. Nesse contexto, dir-se-ia que, ao desativar constrangimentos físicos das ações de transferência de informação, colocam-se em relevo outros problemas e possibilidades de recuperação e busca de informação. Ocupa-se assim da comunicação de informação entre diferentes comunidades de interlocução, das quais a comunicação multicultural seria um caso e, quiçá também, um paradigma, indagando-se acerca dos usos metafóricos da linguagem como novas categorias de entendimento e descrição das ações de informação.

\section{Palavras-chave}

Linguagem; Informação; Recuperação da informação; Busca de informação; Diáspora digital.

\section{New technological frontiers of information actions: Questions and approaches}

\begin{abstract}
Significant changes in the concepts and approaches regarding information and communication have been taking place at the same time as the relationship between language uses and the technological mediations of such uses are also changing - although not in a causal way. The same has happened with the reformulation of information devices due to the increasing convergence of cultural and reproduction technologies and digital technologies. In this context, we can say that, when deactivating the physical constraints of information-transfer actions, other problems and possibilities of information search and retrieval arise. Thus, we deal with information communication among different interlocution communities, of which multicultural communication is a case as well as, perhaps, a paradigm, raising questions about metaphoric uses of language as new categories for understanding and describing information actions.

\section{Keywords}

Language; Information; Information retrieval; Information seeking; Digital diaspora.

\section{INTRODUÇÃO}

Existiria certa homologia entre o estabelecimento de novas relações entre a linguagem e as tecnologias de informação e comunicação e os temas e questões que se estudam na ciência da informação. A introdução e expansão da imprensa no Ocidente foram sintoma e condição da mudança da relação entre os discursos sociais e a narrativa tradicional ${ }^{*}$; a diversificação e a expansão das bibliotecas como públicas e especializadas geraram um campo novo de experimentação, promovendo o aparecimento de enfoques teóricos acerca da organização do conhecimento e da representação da informação. Do início à metade do século XX, as inovações da fotografia, do rádio, do cinema reformularam os espaços do texto e da memória, renovando os saberes em torno dos sistemas sociais de comunicação e alargando-os com novas zonas de indagação e reflexão. Entre essas questões, algumas alertavam acerca da importância do controle e gestão de massas documentais cada vez mais volumosas e diversificadas. A passagem das "tecnologias culturais e de reprodução"** às denominadas "tecnologias intelectuais" de suporte digital ${ }^{* * *}$ modificaria novamente as formas de inscrição, armazenagem e transmissão da produção social discursiva, modificando-se ao mesmo tempo as possibilidades e demandas de intervenção institucional, técnica e profissional no tratamento, circulação e gestão dessa produção.

Podemos denominar as configurações combinatórias de linguagem, tecnologia e informação, de modo genérico,

\footnotetext{
* Dando lugar, por exemplo, a uma reclassificação social das pessoas em letradas ou analfabetas.

** Denominamos "tecnologias culturais", de acordo com Suzanne Briet, a imprensa, a fotografia, a reprografia, o cinema, o rádio, e agregamos "tecnologias de reprodução", segundo Benjamin.

*** De acordo agora com Pierre Levy (2001), denominamos tecnologias inteletuais aquelas que "aumentam e modificam" nossas capacidades cognitivas". O autor inclui, entre as tecnologias inteletuais, sistemas lógicos, de cálculo, técnicas de comunicação e de tratamento e representação da informação. Dentre elas, destacam-se hoje as tecnologias inteletuais em suporte digital: "Favorece(m), ainda, o desenvolvimento e manutenção da inteligência coletiva, pois exteriorizando uma parte de nossas operações coletivas as tornam (...) públicas e partilháveis".
} 
dispositivo de informação*, incluindo as atividades e instituições sociais relacionadas com a recuperação e busca de informação.

Algumas das mudanças mais significativas desses dispositivos estariam hoje na coexistência de instrumentos e procedimentos formais e sistêmicos de recuperação de informação que utilizam linguagens de indexação, junto a recursos de acesso à informação mediada por dispositivos de processamento automático da linguagem natural. Passamos a utilizar, cada vez com maior freqüência, os motores de busca, os diretórios de acesso on-line, as bibliotecas digitais, os opens archives, que facilitam ou dão acesso direto a bases de dados de texto completo.

Nas últimas décadas, a recuperação de informação tem ocorrido em duas etapas (two steps information retrieval). A primeira consistiria em um dispositivo de representação que descreve, sumariza e codifica as fontes primárias de informação para facilitar sua busca seletiva e sua localização efetiva. São assim construídas representações - temáticas e não-temáticas - que oferecem diferentes pontos de acesso às fontes primárias de informação: tema, autor, título, palavras-chave ou descritores, resumo etc. (Hjorland, 2002). Em função dos artifícios da representação da informação, pode em cada caso avaliar-se o resultado da busca sistêmica (information search), antecipando-se o julgamento de pertinência e relevância do destinatário da informação, para escolher a seguir aquelas referências oferecidas pelo sistema que melhor corresponderiam à pergunta formulada. A segunda etapa, logo, seria a localização e disponibilição das fontes primárias escolhidas, nelas mesmas, dando acesso a seu texto completo.

Ora, em um novo cenário de buscas não-formalizadas por regras sistêmicas (information seeking), seria agora indispensável conhecer o modo como as pessoas definem, criam e buscam informação e as condições que facilitam ou inibem seu acesso nos cotidianos de geração e uso de informação. Marchionini (apud Turnbull, 1995) define busca de informação (information seeking) como "um processo deslanchado propositivamente pelas pessoas para mudar seu estado de conhecimento".

* Entendemos por dispositivo de informação um modo de configuração do espaço-tempo ou do tempo que age como uma matriz organizadora das operações concretas de geração, transmissão e uso de informação. Etimologicamente, o termo latino dispositio seria a tradução do termo grego diathesis (usado por Aristóteles, Metafísica, 10, 22 B1) e definido na filosofia moderna como aquilo que facilita, faz algo possível ou limita as possibilidades de algo. Em nosso trabalho, utilizamos o termo a partir de sua leitura por Foucault (Gonzalez de Gómez, 1996).
A busca de informação tem como centro o usuário e os procedimentos heurísticos com que indaga e manipula os recursos de informação*:

- está orientada por uma finalidade que requer compreensão e mudança de um estado prévio de conhecimento;

- as estratégias de busca seriam mais oportunísticas, não-planejadas;

- atende a procedimentos e estruturas de interação;

- o julgamento de relevância acompanha cada passo da busca e pode efetuar-se pelo acesso direto ao texto completo, e não só a partir de suas representações.

Diferencia-se assim da recuperação de informação, que historicamente estaria concentrada nos sistemas de informação e teria todas ou algumas das seguintes características:

- trata-se de uma ação planejada de uso de fontes definidas de informação;

- implica algum conhecimento a priori da informação a ser processada;

- as questões devem ser traduzidas em uma linguagem do sistema e as estratégias de busca (search) atendem a possibilidades preestabelecidas;

- o sistema possui formas de aferir os resultados e apurar o desempenho da busca.

Neste cenário, analisamos alguns dos pressupostos no domínio da organização do conhecimento** e da recuperação da informação. Um sistema de recuperação de informação tem como objetivo o controle e acesso planejado a fontes determinadas de informação, visando a seu uso e transformação gnosiológica e comunicacional. Trabalha, para isso, em dois níveis de linguagem. Uma linguagem de informação preferencial construída e adotada pelo sistema, que vai agir como metalinguagem sobre as linguagens naturais ou profissionais utilizadas por suas fontes de informação e por seus usuários. Tratando-se de recuperação de informação em duas etapas, a linguagem formalizada do sistema (incluindo

\footnotetext{
* Remetemos aqui à citacão de Saracevic (1988a;1988b; 1988c apud Turnbull, 2002), modificada para destacar pontos de interesse para nosso estudo.

** De maneira geral e introdutória, consideramos "organização do conhecimento" ao modo pelo qual os conhecimentos se relacionam e se diferenciam nas práticas de sua produção e uso (González de Gomez, 1996).
} 
das linguagens documentárias aos metadados) constituise com a intenção de homogeneizar e regular os usos das linguagens de suas fontes e de seus usuários. Procede assim pela construção de uma linguagem sistêmica, equacionando aspectos econômicos e tecnológicos, a partir de variáveis que privilegiam, em geral, as invariâncias morfológicas e sintáticas da linguagem.

Pode-se considerar quais as mudanças na definição das condições lingüísticas de acesso à informação, em ambientes de redes eletrônicas, com a possibilidade de acesso a textos completos e hipertextos, as quais desativariam algumas das condições da recuperação da informação em duas etapas. Os pontos de acesso à informação em redes eletrônicas, por exemplo, poderiam considerar outros parâmetros discursivos ou textuais, sem privilegiar somente o nível das palavras ou do vocabulário e da terminologia.

As questões, além de complexas, dependem das culturas informacionais que se entrecruzam e justapõem na Internet. Nelas se estariam formulando e redefinindo novas "superfícies" metainformacionais, de modo que os novos dispositivos de recuperação e busca de informação são tanto condição quanto o campo de experimentação de novas práticas de informação.

\section{AMPLIANDO CONCEPÇÕES: IMPORTÂNCIA DA LINGUAGEM E DA COMUNICAÇÃO}

A relação entre a linguagem, a comunicação e a informação tem sido tratada nos últimos tempos em múltiplas abordagens, que podem agregar-se em duas grandes linhas de indagação: a) da linguagem como dimensão dos dispositivos de tratamento da informação, seja do ponto de visa de sua concepção, como os estudos da lingüística computacional e do processamento da linguagem natural (Bar Hillel, Sparck Jones, entre outros), seja do ponto de vista crítico de estudos que têm como ponto de partida a filosofia da linguagem de Wittgenstein (Blair, Frohmann) ou a teoria da ação comunicativa de Habermas (Lytinnien, entre outros); b) da linguagem como dimensão das práticas e ações de informação dos sujeitos e das organizações, tal como na abordagem da produção de sentido (Brenda Dervin) e outros estudos da significação incorporados à análise de domínio (Hjorland, Albrechtsen), a análise do discurso (Frohmann) e as abordagens socioantropológicas das redes sociais e informacionais (Star, Bowker, Agree). Veremos, porém, que é necessário, cada vez mais, cruzar também as diferentes linhas de indagação.
Hojrland afirma, por outro lado, que questões referentes à significação e à dimensão informacional da vida social deveriam identificar a "frente da pesquisa" em ciência da informação. E não seria para distanciar a informação da tecnologia, mas justamente para reformular e otimizar as alianças entre pessoas, informações e meios.

Da modernidade aos nossos dias, só temos visto crescer e diversificar-se o amplo espectro de ofertas informacionais, institucionais e tecnológicas. Instituições científicas, sistemas de informação, museus, bibliotecas, arquivos e instituições mediáticas partilham características com instituições de comunicação e informação.

Veron (2000) estabelece uma comparação entre a produção de informação das instituições científicas e a mídia:

“(...) uma instituição científica parece-se em fim a um meio, mais especificamente a uma instituição mediática de informação, por exemplo, a uma cadeia de televisão em sua função informativa. Qual é o input, num caso e no outro, que coloca em andamento o processo de produção? A informação em forma de discurso. Qual o output, após a utilização de máquinas mais ou menos sofisticadas? A informação em forma de discurso. Num caso e outro, os discursos na entrada e na saída não são idênticos: têm acontecido, entre a entrada e a saída, transformações. E tanto a instituição científica como a instituição mediática informativa dizem falar-nos de uma realidade, a qual chamamos mundo" (Veron, 2000).

Lyytinen (1987) oferece um enfoque interessante, ao considerar um sistema de informação como instituição comunicativa, afirmando que se assemelha a "um meio de comunicação de massa para um grupo local”. Para o autor, a criação de cada sistema de informação daria origem ou atualização a uma instituição de comunicação que intervém no meio social por meio de atividades de modelagem informacional: "um sistema de informação é um instrumento lingüístico de comunicação” (Lyytinen, 1996, p. 14).

Levy (1993) estabelece uma correlação biunívoca entre as instituições e as tecnologias intelectuais.

"Uma vez que são convencionais e historicamente datadas, é claro que as tecnologias intelectuais (a escrita, a informática) são instituições. Embora talvez se aceite que toda instituição seja considerada com uma tecnologia intelectual" (Levy, 1993). 
Lyytinen, ainda que não se detenha sobre a questão, identifica o sistema de informação não com os quadros macroinstitucionais, mas por sua inserção como "mídia local” em um contexto organizacional determinado. Daí que as premissas de concepção do sistema remetem à significação e à organização*.

Destacamos, desta compreensão do Sistema de Informação (SI), a importância das significações compartilhadas em um contexto organizacional, o que justificaria a introdução de um estrato intermediário na modelagem do sistema, consistindo em uma descrição estável e centralizada do significado dos dados organizada em um esquema conceitual. O desenvolvimento dessa instância intermediária de modelagem denominar-se-ia "modelização da informação" (information modeling). A "modelização da informação" seria assim diferenciada da "modelagem de dados" (data modeling), desenvolvida na década de 70 com o objetivo de descrever uma estrutura para o acesso e armazenagem de dados em meio digital (em árvore, relacional, em rede). Uma vez que a comunicação mediada pelo sistema de informação estaria sujeita às condições do uso local da linguagem de cunho organizacional, que restringiria as possibilidades enunciativas da linguagem natural, toda regra do sistema deverá conjugar regras técnicas e acordos comunicacionais.

"O uso de um SI consiste em ações, atos de discurso ou atos comunicacionais os quais acontecem enquanto fazem algo significativo para os usuários do SI" (Lyytinen, 1987, p. 16).

Um SI deveria considerar-se como um sistema social tecnicamente disponibilizado: inserido na ação; contextualizado e institucionalizado; propositalmente desenvolvido e sempre em desenvolvimento (sujeito a mudanças). A institucionalização, porém, só pode atuar a posteriori sobre um campo de ação e interpretação formado por práticas sociais.

"Isto é chamado forma de vida pelo último Wittgenstein, que mostra que um tal conjunto de práticas é o pano de fundo necessário do uso significativo da linguagem" (Lyytinen, 1987, p. 16).

\footnotetext{
* Quando falamos de dispositivos de informação designando os lugares materiais e imateriais de inscrição de informações e operações metainformacionais, remetemo-nos a matrizes tecnossociais que, ainda quando instaladas em nichos institucionais, mantêm sua autonomia em relação à instituição, de modo que um mesmo dispositivo pode constituir-se em diferentes contextos institucionais, e uma mesma instituição pode acolher diversos dispositivos. Ficamos assim mais perto do uso de Levy que o de Lytinnien, que parte da inserção concreta do sistema de informação em uma organização.
}

A compreensão de uma mensagem não pode separar-se das práticas sociais em que são trocadas comunicacionalmente essas mensagens.

"Tudo sugere que a modelagem informacional (information modeling) constitui uma atividade pela qual uma instituição de comunicação é criada e mantida. O sucesso da modelagem informacional, por outro lado, depende da disponibilidade de um mecanismo que estipule sua aceitação pela instituição, assim como da extensão em que tal instituição esteja em harmonia com a forma de vida na qual está inserida" ( Lyytinen, 1987, p. 16).

Para Lyytinen (1987), conceber um sistema de informação requer logo compreender esse duplo arcabouço de sua constituição: a forma de vida que visa a sustentar ou a modificar pela regulação dos fluxos de informação; sua inclusão organizacional, que define sua funcionalidade como instituição comunicacional de caráter local.

“(...) um SI é uma instituição social. Ele cria uma classificação de tipos de atos e de atores que se reconhecem e sustentam reciprocamente. São assim reforçadas aquelas formas de uso do SI acerca das quais existe acordo"... "O significado das mensagens produzidos no SI não pode ser separado das ações humanas que produzem as mensagens (...)".

O desenvolvimento da linguagem formalizada do sistema requer reconstruir as condições formais que fazem de um conteúdo significativo uma enunciação útil em um contexto social determinado.

"Nesta perspectiva, os sistemas de informação desempenham e possibilitam um conjunto limitado de comportamentos humanos de caráter lingüístico, a ser mediado por tecnologias de informação, e conforme uma classe específica de discurso (...) a modelagem informacional deverá ser vista como um estudo do significado das mensagens (expresso em atos de enunciação) e das propriedades formais de um ato de enunciação e suas combinações (Discurso)" (Lyytinen, 1987, p. 15).

Um sistema de informação, logo, operaria como um dispositivo orientado a gerar uma mudança de linguagem, em um contexto local e organizacional definido. De fato, a partir da década de 80 , percebe-se uma mudança na concepção dos modelos dos sistemas de informação. $\mathrm{O}$ ponto de partida não seria necessariamente uma premissa ontológica, que legitime e preserve a relação unívoca entre a linguagem do sistema de informação e o universo de discurso que o remete ao mundo do informado. Lyytinen (1987) incorpora essa concepção da modelagem. 
Para o autor, existiriam duas principais abordagens sobre a concepção de sistemas de informação, com diferentes premissas acerca de qual seria a "matéria-prima” a ser operacionalizada pelo sistema. Uma, a "visão do mapeamento do real", supõe um processo de mapeamento que se desenvolve entre o "mundo real" e um "modelo formal" ou esquema conceitual, que seria a "representação do mundo real". Os modelos de informação seriam semelhantes aos modelos observacionais e homeomórficos das engenharias (Lyytinen, 1987, p. 9). Os sistemas de informação que tiverem como ponto de partida um pressuposto objetivista ou ontológico estariam mais preocupados em como representar, e não que e para que representar. Para Lyytinen, trata-se de pressupostos epistemológicos próprios de um realismo ingênuo (Lyytinen, 1987, 10).

Na outra abordagem, de "desenvolvimento de uma linguagem formal”, a modelagem de informação é considerada como um processo comunicacional e interativo no qual são formuladas, desenvolvidas e adotadas regras convencionais. Tais regras especificariam o conteúdo, forma e usos das mensagens cuja comunicação é mediada pelo sistema de informação e cuja linguagem seria codificada conforme as normas e usos organizacionais antes que pela lógica formal.

Entendido como "instrumento lingüístico de comunicação”, um sistema de informação consistiria “(...) em diferentes grupos de pessoas se comunicando em uma linguagem formal" (Lyytinen, 1987, p.14). A linguagem formal codifica as mensagens que são intercambiados entre os membros de uma organização.

"A comunicação através do SI cria, controla e dá sustentabilidade às interações sociais num contexto organizacional. $\mathrm{O}$ caráter específico de um sistema de informação como meio de comunicação deriva da natureza formal de sua linguagem e dos modos preestabelecidos de seu uso" (Lyytinen, 1987, p.14).

Para essas "linguagens profissionais", seriam decisivos tanto os hábitos e usos dos participantes quanto as regras organizacionais de regulamentação das mensagens. De fato, a formalização da linguagem sistêmica deve acompanhar processos de comunicação organizacional concernente a assuntos centrais para suas atividades. Isto permite um entendimento comum de tópicos importantes para todos os envolvidos nas mesmas e permite diminuir o esforço em tarefas rotinizadas.

Ao mesmo tempo, à medida que os objetivos dos sistemas de informação forem resultado de políticas organizacionais e não de um consenso comunicacional e cooperativo de todos os seus desenhadores e usuários, a indução do consenso produzido por meios de "poder" ou "administrativos" pode, pelo contrário, gerar conflitos ou aumentar conflitos já existentes. Em qualquer caso, a modelagem informacional faz explícitas e inteligíveis as práticas de comunicação e informação em seus contextos de intervenção, colocando em evidência alguns dos mecanismos pelos quais um uso da linguagem inicia, reforça e controla comportamentos organizacionais. Permitiria, assim, esclarecer os aspetos mais "políticos" dos fluxos de informação, ao detectar distorções e inconsistências na comunicação - assim como os aspectos disfuncionais das definições da linguagem sistêmica, enquanto incompatíveis com outras definições e regras organizacionais (Lyytinen, 1987, p. 17).

Lyytinien está entre os que contribuem para estabelecer a importância da linguagem e da comunicação no desempenho e eficácia dos sistemas de informação. Sua abordagem inclui todo tipo de sistema, com ênfases em seu contexto organizacional: a) os gerados em ambientes de pesquisa, administrativos ou conforme outras demandas institucionais; b) os que processam preferencialmente textos, como os de recuperação de informação em duas etapas, e os que processam informações factuais, como os sistemas de informação epidemiológica. Especifica, ao mesmo tempo, o caráter convencional do quadro normativo que condiciona os usos da linguagem em contextos organizacionais singulares. Essa aproximação da semântica à pragmática estabelece novas homologias entre as linguagens definidas pelos profissionais de informação e as linguagens daqueles que geram e usam as informações*. Se isso significa, para alguns, que todo modelo seria uma representação, para outros significa, também, que todas as representações seriam modelos.

Desta forma, Lytinnien coloca em evidência, ao mesmo tempo, algumas das restrições dos estudos da linguagem

\footnotetext{
${ }^{8}$ Nas linguagens documentárias, a questão do caráter contextual da significação está presente ainda que mais bem tácita nas práticas profissionais documentárias, como efeito de trabalho com os textos. Diferente das experiências de modelagens no processamento de dados, que tem como referentes os mundos das coisas e as atividades próprias da esfera da produção, do comércio e das finanças, a Documentação lida com o significado e a discursividade em relação direta com a textualidade. Nos modelos dos analistas de sistemas e programadores, o caráter imediatamente impessoal e objetivo do "dado" e de sua referência (estoques de matérias-primas, planilhas de salários, cadastros de clientes), a tendência é buscar como referência dos modelos uma ontologia do mundo real, favorecendo o obscurecimento da discursividade e da semanticidade de seus processos de modelagens.
} 
nas abordagens tradicionais da recuperação da informação. De fato, o que está em jogo não é agora a definição da linguagem sistêmica, mas a própria concepção do sistema como unidade de análise da relação linguagem - recuperação de informação.

Poderíamos afirmar que as questões nucleares dos estudos da documentação e da informação dirigiam-se aos modos de produção e distribuição dos conhecimentos sociais dominantes desde a modernidade. O desenho dos sistemas de informação visava à reutilização e reapresentação seletiva de um repertório intelectual e cultural disponibilizado conforme os regimes de informação estabelecidos. O modus operandi dos mesmos gerava, ao mesmo tempo, grandes estoques organizacionais de informação e múltiplos efeitos de dispersão.

As bases de dados referenciais, umas das primeiras aplicações dos computadores ao processamento das palavras, ofereciam-se como facilitadoras do acesso à informação além dos limites das coleções e dos acervos organizacionais, no escopo e abrangência de uma extensão ideal que corresponderia à "literatura de uma área do conhecimento”. Em segundo lugar, vinculando literaturas, autores e regiões editoriais, a base de dados referenciais se estabeleceria como instrumento de uma "cartografia administrativa", oferecendo um mapa virtual da produtividade científica de instituições e pesquisadores (González de Gomez, 2003).

Nesse sentido, poderíamos dizer que, no início do século XXI, a crescente convergência tecnológica tem favorecido antes a reformulação que a solução de muitas das questões prévias. Hoje seguem existindo os problemas da reunião significativa de informações pertinentes e relevantes para uma questão e da exclusão do acesso às informações potencialmente públicas e livres, da maior parte da população; somam-se a estes outros problemas que denominaríamos "diáspora digital".

A Internet junta textos e inscrições documentárias, ao mesmo tempo em que desloca os sujeitos que a acessam de seus lugares de enunciação de ponto de partida, colocando-os em contextos heterológicos e polinômicos. Ao mesmo tempo, a Internet é um meio geralmente opaco em relação às suas próprias condições de produção. Assim como os imigrantes, que, ao deixar suas "casas" estão obrigados "a negociar com as novas culturas em que vivem, sem simplesmente serem assimilados por elas”, o internauta, ao deixar a casa de sua linguagem e de suas comunidades habituais de interlocução, teria uma experiência diaspórica, defrontando-se em muitos casos com uma fronteira ideal que o coloca entre a polinomia e a anomia, tendo de construir sua autonomia informacional, ao mesmo tempo em que lida com os exercícios instáveis de ambigüidade e cooperação demandados pela tradução. Neste caso, como utilizamos a linguagem quando lidamos com recursos de informação onde existem múltiplos contextos semânticos, epistemológicos, normativos?

\section{DA RACIONALIDADE SISTÊMICA AO CARÁTER ESTRATIFICADO}

Os estudos de Lytinnien, que introduziriam conceitos da teoria da ação comunicativa de Habermas ao domínio da concepção de sistemas, além de colocar em relevo o carácter comunicacional do SI, introduzem elementos críticos nas visões racionalistas de transparência do sistema.

No contexto das redes hipermídia e interativas, seria mais difícil ainda manter as premissas lineares do racionalismo sistêmico: as condições econômicas, políticas e sociais desdobram-se em complexas infraestruturas e dispositivos tecnológicos, produzem transformações comunicativas e informacionais nãointencionalizadas nem sempre visíveis para os agentes imediatos da enunciação ou destinação. Se, no escopo e abrangência delimitados do sistema de informação convencional, os que se comunicam não possuem a total inteligibilidade de seus processos de comunicação, no cenário das redes seria maior a opacidade das infraestruturas e marcos normativos. No desenvolvimento desses dispositivos, normas e infra-estruturas, intervêm múltiplos atores, com diferentes competências e interesses, cujas concepções e procedimentos interceptam diferentes instâncias e dimensões das possibilidades de comunicação e informação.

Nessa direção, interessa-nos considerar melhor o caráter estratificado das ações de informação, das quais o sistema seria tanto uma de suas instrumentalizações quanto sua idealização. Também neste caso, ao suprimir ou deslocar restrições físicas, a comunicação a distância e interativa, a Internet, colocaria em evidência outros constrangimentos que resultam ora dos hábitos e práticas de informação, ora das premissas teóricas e procedimentais nas quais se embasam os desenhos e a gestão de artefatos de informação.

Em diferentes trabalhos (1996; 2000; 2003), apresentamos nossa abordagem estratificada das ações de informação, a partir de uma experimentação idealizada, buscando construir uma concepção genérica e abstrata à qual pudessem referir-se as práticas informacionais cotidianas 
de um homem comum, as práticas paradigmáticas dos cientistas e as atividades configuradoras dos serviços, sistemas e redes de informação.

Em Bates (2002), encontramos um "modelo em cascata" dos "componentes de recuperação de informação", no contexto de meios eletrônicos, que reforça a oportunidade de nossa abordagem*. Os "estratos" de um componente de recuperação interagem entre si de maneira sinérgica, neutra ou conflitual. Trata-se de uma "cascata" de interações que culmina na interface, mas na qual a interface não emerge na fase de finalização, porém organiza todas as escolhas e soluções adotadas em cada um dos estratos que trabalham na produção de um efeito de recuperação de informação. Nesse sentido, não há estrato superior que seja eficaz, se não houver interação efetiva com os que lhe estariam subordinados. Um motor de busca potente não seria efetivo, por exemplo, se as tecnologias de acesso não fossem suficientemente capacitadas para aproveitar sua velocidade de processamento. Uma das zonas problemáticas ficaria situada na integração das informações subjacentes às "superfícies" de metadatos com que são apresentadas e às capacidades de busca dos usuários.

$\mathrm{O}$ modelo em cascata não remete ao design de um web site nem de uma intranet, nem de qualquer outra tecnologia específica. Trata-se de um modelo referente a qualquer componente de recuperação inserido em um recurso eletrônico de informação. Isolando tal "componente de recuperação" de contextos organizacionais e técnicos estruturados, Bates elimina da discussão algumas das premissas que singularizam o "sistema de recuperação de informação". Propõe-se colocar ênfase nos componentes não-técnicos: as informações e o usuário. Essa centralidade do usuário e das informações que lhe são relevantes seria o princípio que outorgaria visibilidade e função aos estratos (layers) que operam na recuperação e busca de informação**.

\footnotetext{
* O modelo de Bates constrói um conceito generalizado de "componente de recuperação" que poderia estar sediado em diferentes unidades de comunicação e informação, sem ter a característica de uma subunidade funcional de um sistema único. Nossa abordagem se diferencia por querer estender a concepção dos estratos, não restrita ao desenho e implementação de um dispositivo formalizado de informação, mas a todas as práticas e ações sociais de informação envolvendo qualquer tipo de mediação material e cultural, formal ou informal.

** "The Cascade model describes the several design layers that have to be taken into account in the process of developing and implementing an information system in an automated environment. Starting with the interface, imagine turning that interface on its side and pulling it apart, like an accordion, to reveal the several design layers backing that interface and culminating in the interface" (Bates, 2002).
}

Bates, ao aderir a essa nova direção da modelagem, estaria preocupada com as modalidades de integração das diversas e divergentes "perícias" envolvidas na concepção dos "estratos" do SI, organizando-os em torno da centralidade do usuário e da informação como polaridades dominantes dessa concepção. Isto implica, porém, que os que desenham cada um desses layers podem fazê-lo com diferentes objetivos e pontos de vista. Esses diferenciais de concepção poderão levar a resultados ineficientes ou à subotimização do dispositivo de informação, já que os "estratos" agem no modo de uma "cascata", de modo que o que se faz em um estrato bem ou de modo inadequado - afetará o próximo, que afetará o seguinte, e assim sucessivamente, alcançando todos os estratos. A escolha de uma estrutura para uma base de dados e a seleção dos conteúdos informacionais digitalizados serão fatores decisivos para a recuperação e busca de informação, inseparáveis ao mesmo tempo das fases específicas do tratamento da informação, como o uso de metadatos ou linguagens de indexação.

Bates adota assim um modelo de Hildreth* para descrever os estratos principais do sistema de informação. Conforme o mesmo, seriam quatro as zonas ou estratos que agregariam "cascatas" de ações de informação e requerem formas específicas de intervenção e modelagem: a) infra-estrutura técnica; b) conteúdo / informação; c) tratamento da informação e construção de interfaces; d) usuário e práticas de busca de informação. A autora destaca o papel dos tecnólogos e profissionais de informação na definição e implementação de muitas das ações envolvidas na constituição desses estratos.

Para Bates, uma pessoa sozinha não poderia dar conta de todas as capacidades e conhecimentos necessários para conceber e articular todos os estratos de um componente de recuperação, mas, ao mesmo tempo, os que trabalham em cada uma dessas camadas não reconhecem as funções e procedimentos constitutivos dos outros estratos**. O desenvolvimento das bibliotecas digitais requer com urgência essa maior compreensão

\footnotetext{
* Trata-se de um modelo para busca em catálogs on-line, de Hildreth (1982, Fig. 12, p. 114).

** “(...)Yet much of the discussion in the digital library world regarding metadata seems to presume that the intellectual structure guiding the design and application of the metadata is of little import. In the Dublin Core, "subject" is just one generic category among fifteen (Weibel \& Lagoze, 1997). If there are four different types of subject description applied to each document - a situation not at all unlikely - each designed on different principles, they will all be lumped together in the repeating fields of that category. For good retrieval, however, they may each need a different kind of retrieval mechanism and presentation in the interface" (Bates, 2002).
} 
da estratificação e das relações entre os estratos, já que nelas se superpõem plurais estratos cada vez mais numerosos e sofisticados.

Em nosso trabalho, após estudar diferentes teorias acerca da ação social, do ato de enunciação e da ação comunicativa, optamos por generalizar o conceito de "ação de transferência de informação", de modo a não restringi-la a ações formalizadas e instrumentalizadas por um sistema de informação e poder aplicá-lo a diferentes modalidades de ações. Ao considerar que uma ação de informação, nas sociedades complexas ou pósconvencionais, definiria um conjunto de estratos ou planos a serem articulados, preocupavam-nos as questões derivadas da assimetria desses estratos.

Em nossa concepção, um dos planos da ação de informação definiria as regras sociais de sua produção a partir das quais podem ser recortadas as condições de sua emissão e transmissão e as possibilidades e alternativas de relacionamento entre duas ou mais informações e suas inscrições. Trata-se de um estrato regulador que estipula o domínio relacional ou o contexto a partir do qual uma operação informacional pode desenvolver valores testemunhais ou cognitivos. Pode-se chamar a este plano que inclui a informação sobre a informação de "metainformação". Não se trata, porém, de um plano transcendental ou de um a priori que tem plena inteligibilidade e poder regulador dos planos a que remete como seu plano-objeto. Trata-se de uma orientação preferencial da práxis, buscando definir e organizar as múltiplas dimensões e contextos de uma ação de informação, visando à obtenção de um fim, à satisfação de um interesse, à realização de um projeto, ou de um plano de ação.

Por outro lado, a informação responde a condições daquilo acerca do qual informa, estabelecendo relações de alteridade e diferenciando com uma ordem cultural, cognitiva, ética e estética, na qual estão enraizadas suas referências semânticas e existenciais; remete, neste sentido, a uma formação discursiva e seus universos de referência. Pode-se denominar a esta linha de articulação simplesmente "informação".

Finalmente, toda ação de informação que constrói um valor de informação age a partir de um hábito ou memória de ações de informação, que a precede, ora de modo tácito ou intencional, institucionalizado ou informal, e que se fixa e reproduz em um plexo de instrumentos e meios disponibilizados pelo ambiente cultural. Para referirmo-nos a tudo aquilo que disponibiliza e deixa disponível, como mediação das mediações, um valor de informação, falamos de "dispositivo de informação". Quando enfatizamos o lado de "cultura material", falamos de "artefatos de informação".

Nesse contexto, denominamos informação* àquilo que constitui uma ação de informação: sempre seria assim informação para algo e para alguém. Logo, toda informação se constitui como que em possibilidades de sentido que sempre sobrepassam aquele que foi intencionalizado em sua constituição e fica entrançada nos estratos anônimos e opacos de caráter tecnomateriais que the outorgam durabilidade e atualizam as condições de sua comunicação e translação. Neste trabalho, interessa-nos destacar uma assimetria constitucional entre o estrato infra-estrutural da informação e seus estratos semânticos e pragmáticos.

Se retornarmos à nossa representação estratificada das ações de informação, a partir das premissas enunciadas, poderíamos dizer que um valor, evidência ou testemunho de informação: a) no ponto de vista do estrato semântico-pragmático, constitui, conforme regras e usos intersubjetivos, uma profusão de narrativas e ontologias culturais polimórficas; b) do ponto de vista do estrato regulatório ou estrato metainformacional, constitui, por regras formalizadas, padrões convencionais e contratos; c) do ponto de vista do estrato infraestrutural ou estrato tecnológico, teríamos a definição de padrões ou tipos de ações pré-modeladas ou que tomam sua forma de exemplos prévios de ação (tal como discar em um telefone ou "clicar" um ícone de impressora para enviar a ordem "imprimir"), conforme princípios mimeomórficos ou homeomórficos.

Uma das principais manifestações de assimetria** ficaria constituída entre os estratos de geração e uso de informação, nos quais se desenvolvem as narrativas sociais, e os estratos definidos pelas condições tecnoeconômicas de interoperabilidade que obedecem

\footnotetext{
* Retomando outros trabalhos, consideramos como alguns dos traços do que se denomina informação: 1) seria "indeterminada a priori" dado o caráter cultural e simbólico das formas humanas de experimentar e de partilhar suas experiências com o mundo natural e social; 2) não poderia ser fixa (predefinida somente ao nível do código ou inscrição), mas tampouco relativa (impossível de enquadrarse em expectativas sociais nem em memórias acessíveis), e sim "relacional", agindo como um dos operadores de relação em domínios estéticos e discursivos; 3) diferenciar-se-ia da significação, do discurso e também dos documentos, à medida que a ação de informação relaciona a produção de sentido, a construção discursiva de sua referencialidade social e existencial e as mediações que permitem e regulam sua disponibilidade social.

** Utilizamos aqui os conceitos de Collins \& Kush, os quais diferenciam ações polimórficas e homeomórficas ou mimeomórficas. Ações polimórficas são aquelas que só podem ser compreendidas
} 
a definições genéricas e padronizadas. Uma atividade social de informação, porém, seria sempre uma conjugação de ações polimórficas e mimeomórficas. Dissociados, cada um dos estratos parece atender a uma finalidade e uma programação por vezes opostas e divergentes; cada um deles, porém, demanda e é demandado pelos outros.

A partir destas considerações, diremos que práticas e atividades sociais de informação são combinações híbridas de ações polimórficas e mimeomórficas que requerem ser olhadas em todas as suas dimensões e estratos para serem entendidas, modificadas, facilitadas. A equação dessas ações polimórficas e homeomórficas seria, assim, um dos pontos a serem trabalhados conjuntamente pelos estudos da lingüística, da computação e da ciência da informação.

\section{DISSOLUÇÃO DE PREMISSAS COMUNICAC̣̃̃O CIENTÍFICA}

NA

Existem outras concepções introduzidas na ciência da informação, sem muita crítica, que reforçam a linearidade e reducionismo do racionalismo sistêmico simplificador, tal como a ênfase nos esquemas disciplinares e o pressuposto do consenso das comunidades científicas.

A pergunta pela vinculação dos conhecimentos, na epistemologia tradicional e normativa, esteve sempre associada à afirmação da unidade da ciência, constituída em torno de um sujeito racional universal. A partir de Peirce, observaríamos a substituição do conceito de sujeito racional e abstrato - logo, transindividual e transcultural - pelo conceito hoje generalizado de "comunidade" científica.

Desde o ponto de vista sociológico, uma diferenciação clássica de comunidade e sociedade é a formulada no século XIX, por Ferdinand Tonnies,

“(..) gemeinschaft é uma comunidade de pessoas que partilham o lugar ou os interesses, enquanto gesellschaft

por quem participa de uma cultura ou forma de vida. São ações que podem ser executadas conforme um número indefinido de comportamentos, e, ao mesmo tempo, uma mesma instância de comportamento pode dar lugar a muitas e diferentes ações. Dado que são ações determinadas por regras, o modo correto de realizá-las só é possível para quem participa da forma de vida que contextualiza a ação. Envolvem, assim, uma variedade de comportamentos para executar a mesma ação na mesma situação (Collins \& Kush, 1999, p.19).

Ações mimeomórficas seriam aquelas que podem ser reproduzidas por um observador externo sem compreensão da ação, do mesmo modo em que poderiam ser reproduzidas por alguém que compreende a ação (Collins \& Kush, 1999, p.21). Tratamos disto em outros trabalhos (González de Gomez, 2000, 2003 c). é uma sociedade constituída por relações contratuais impessoais entre os cidadãos e sua nação-estado"*.

O conceito de "comunidade científica" deveria conciliar, porém, não só o fatum de uma intersubjetividade constituída no compartilhamento comunicativo de experiências, mas também alguma demanda de validade e objetividade do conhecimento identificado como científico que permitisse projetá-lo além do caso singular e dos limites de experiência de um sujeito situado. Peirce, dentro do que se conhece como a "virada lingüística", introduz o conceito de "comunidade de investigadores" como caso exemplar de uma "comunidade comunicativa ilimitada", conjugando, em um mesmo conceito, a idéia de uma intersubjetividade atual e de um processo permanente e ilimitado de interpretação e aprendizagem. A "prorrogação indefinida" dessa aprendizagem lhe outorgaria certa equivalência com a idéia contrafatual de uma "opinião final" ou de uma apreensão incondicionada da verdade.

Na década de 60, a crítica da ciência favorece o pósempiricismo de Kuhn, que introduz variáveis históricoculturais na descrição das práticas de pesquisa. De maneira mais radical, a transferência da filosofia da linguagem do segundo Wittgenstein para os estudos da ciência levaria Kuhn a afirmar a impossibilidade de uma experiência neutra e a incomensurabilidade das linguagens e das teorias científicas.

A relação biunívoca entre a comunidade dos conhecedores e a "matriz disciplinar" se expressaria tanto nas capacidades incorporadas nos sujeitos e suas práticas (embedded knowledge), quanto em um discurso científico plausivel de registros textuais (conhecimento móbil).

Para Geertz (1997), esses sujeitos coletivos da pesquisa seriam quase "subculturas" ou comunidades biográficas, retomando no viés antropológico as formas de vida ou jogos de linguagem. Na mesma direção, Harry Collins (1998) recupera questões referentes aos critérios de excelência e de validade aceitos em uma comunidade de práticas e discursos, designando os compromissos normativos e os valores partilhados pelos sujeitos coletivos de pesquisa como "culturas de evidência". Em outros trabalhos, relacionamos as "culturas de evidência" dos cientistas com as "sanções coletivas" comunitárias. Tais "culturas de evidência", além de funcionar como instâncias de arbitragem, pareceriam oferecer mediações

\footnotetext{
* "(...) gemeinschaft is a community of shared geography or interests among people, while gesellschaft is a society, constituted by impersonal, contractual relations between citizens and their nationstate" (Tonnies apud Schaefer,1997).
} 
entre as estratégias singulares de cada pesquisador e projeto de pesquisa e as epistemologias institucionais das agencias de financiamento e avaliação de ciência e tecnologia (González de Gómez, 2000).

O cenário atual requer outras considerações. No cada vez mais complexo sistema de ciência e tecnologia, encontram-se problemas para descrever e ainda organizar a produção contemporânea de conhecimentos científicos, à luz das categorias prévias de "disciplina" e "comunidade científica".

De fato, tanto a transdisciplinaridade instrumental e seus projetos orientados por missão, quanto o projeto transdisciplinar de compromissos éticos e políticos defrontar-se-iam com o seguinte paradoxo: se as estruturas transversais de compartilhamento de conhecimentos exigem condições mínimas de reciprocidade e transparência comunicacional - o que seria viável nos contextos prático-discursivos dos mundos de vida compartilhados, de cujas orientações teleológicas participam -, o cruzamento das fronteiras disciplinares e institucionais, como na pesquisa transdisciplinar, traçaria redes heterológicas, figuras complexas de leituras intertextuais e interlinguais.

Outros compromissos metodológicos e normativos incluídos no princípio de autoridade ou autonomia de um campo científico ficariam atingidos nas modalidades da pesquisa inter e transdisciplinar.

O problema não é menor: nas próprias redes de pesquisa, além dos jogos entre jogos de linguagem, próprios da colaboração entre diferentes especialidades e setores, existiriam outros processos de conversão internos ao mesmo programa de pesquisa, tal como entre "jogos de linguagem" textuais e literários e os "jogos experimentais" dos laboratórios.

Se aceitarmos que a produção de conhecimentos requer um sujeito coletivo e não meramente um sujeito psicológico ou individual, uma medida adequada seria partir da noção de grupo. Um grupo* seria um conjunto de indivíduos reunidos por um projeto ou programa de ação que partilham objetivos comuns e que, ao mesmo tempo em que compartilham e constroem práticas,

\footnotetext{
* "O grupo de pesquisa é definido como um conjunto de indivíduos organizados hierarquicamente, cujo fundamento organizador da hierarquia é a experiência, o destaque e a liderança no terreno científico ou tecnológico, e envolvidos profissional e permanentemente com atividades de pesquisa cujo trabalho se organiza em torno de linhas comuns de pesquisa e que, em algum grau, compartilham instalações e equipamentos" (Diretório dos Grupos de Pesquisa, CNPq, censo 2002).
}

experiências e espaços sociais, partilham e constroem uma teia de significados expressa em inscrições e textos documentários.

Segundo Qui, Lancaster \& Allen (1997), as características do grupo interdisciplinar são as seguintes: 1) diferentes corpos de conhecimento estão representados no grupo de pesquisa; 2) os membros do grupo utilizam diferentes abordagens com a finalidade de resolver problemas; 3) os membros do grupo desempenham diferentes papéis para resolver os problemas; 4) os membros do grupo trabalham em um problema comum; 5) a natureza do problema determina a seleção dos participantes do grupo; 6) os membros do grupo são influenciados uns pelos outros no desempenho de suas tarefas.

Ao se tornarem cada vez mais evidentes questões acerca da comensurabilidade e incomensurabilidade dos discursos sociais a serem mediados pelos dispositivos de informação, será preciso procurar novos caminhos de entendimento e descrição. Um deles seria compararmos a situação transdisciplinar com as situações do multiculturalismo e as diaspóricas*.

"O hibridismo não se refere a indivíduos híbridos, que podem ser contrastados com os "tradicionais" e "modernos" como sujeitos plenamente formados. Tratase de um processo de tradução cultural agonístico, uma vez que nunca se completa, mas que permanece em sua indecidibilidade".

Sem configurar ainda teorias, podemos ver que a leitura das zonas transetoriais e transdisciplinares da pesquisa poderiam categorizar-se em duas direções:

a) as que colocam a ênfase nos sujeitos e suas práticas (Almeida Filho, 2000);

b) as que analisam os processos de geração de conhecimento em figuras de compartilhamento e distributivas (Kanfer et alii, 1998).

Se para alguns as alianças intersetoriais e as pesquisas transdisciplinares, intersetoriais e transorganizacionais dependem das pessoas que se deslocam entre mais de um campo de práticas e conhecimentos, e se considera que a produção de conhecimentos transdisciplinares é preferencialmente uma prática dotada de características singulares e irreversíveis, para outros seria tão importante os conhecimentos imersos nas pessoas e nas práticas quanto a geração de procedimentos e meios que permitam

* Seria o caminho sugerido nos trabalhos de Almeida Filho, 2000. 
a mobilização dos conhecimentos entre instituições, disciplinas, grupos, setores de atividade.

Em nosso trabalho, optamos por cercar o conceito de tradução (translação), tal como o encontramos em Callon e Hall. Trata-se da construção de equivalências entre ações, valores e significados, de maneira negociada e renegociada, visando à reformulação de interesses distantes, incomensuráveis, por vezes incertos e instáveis.

Para Hall, " é um processo através do qual se demanda das culturas uma revisão de seus próprios sistemas de referência, normas e valores, pelo distanciamento de suas regras habituais ou "inerentes" de transformação. Ambivalência e antagonismo acompanham cada ato de tradução cultural, pois o negociar com a "diferença do outro" revela uma insuficiência radical de nossos próprios sistemas de significado e significação" (Bhabha apud Hall, 1997, p. 74-75).

Para Callon (2003), "Tradução que faz possível, num sentido geométrico, um "translado" (transport) de conhecimentos, de um ponto ao outro, mas que permite igualmente, e este seria seu sentido lingüístico, uma compreensão entre universos no começo estrangeiros (os de $\mathrm{A}$ e B) a universos que são progressivamente reconfigurados ao mesmo tempo em que se conectam (entre sim). (...) No caso extremo de conhecimentos totalmente emergentes (A é o único agente que os domina)... todo um trabalho de gerar interesse, de enredamento (enrolement), de aliança será necessário para que se constitua uma utilidade para outro agente que não A, agentes que nessa construção mudam suas identidades, daí que falamos da construção de novos atores".

Não se trata de transportar significados por meio de linhas divisórias, como uma mercadoria.

"O tradutor é obrigado a construir o significado na língua original e depois imaginá-lo e modelá-lo uma segunda vez nos materiais da língua com a qual ele ou ela o está transmitindo. As lealdades do tradutor são assim divididas e partidas. Ele tem que ser leal à sintaxe, sensação e estrutura da língua-fonte e fiel àquelas da língua da tradução. (...) Estamos diante de uma dupla escrita (...)" (Sarah Maharaj apud Hall, p.41).

$\mathrm{O}$ que aparece como transversalidades irredutíveis no cenário da cultura pareceria ser, a partir deste século, cenário inevitável no domínio da ciência e da tecnologia.

"Entretanto, o fato é que nem os indivíduos enquanto entidades solidárias livres e sem amarras nem as comunidades enquanto entidades solidárias ocupam por inteiro o espaço social. Cada qual é constituída na relação com aquilo que é outro ou diferente dela própria (ou através dessa relação)" (Hall, 1997).

\section{COMPARTILHAMENTO E AUTONOMIA INFORMACIONAL NAS REDES}

Em algum momento, sem as restrições tecnológicas do meio físico e da distância espacial, podemos pensar que estaria resolvido o velho problema da transferência de informação. Se não na direção de um universo unificado dos conhecimentos, ao menos confiamos em que ficaria facilitada a produção compartilhada de conhecimentos e de sua mobilidade pelas redes tecnossociais.

Nossa contribuição para uma expectativa de solução dependerá, como sempre, da maior acuidade com que consigamos colocar uma significativa pergunta social no cerne de uma investigação cuidadosa.

Kanfer et alii (2000) analisam o processo de mobilização de conhecimentos entre dois grupos constituídos em diferentes campos disciplinares, contextos institucionais e histórias e formação. Consideram ao mesmo tempo as mediações comunicacionais entre os grupos - as infraestruturas de informação.

Os processos de conhecimento seriam analisados como dependentes das variáveis contextuais e comunicacionais.

Os autores analisam três situações modelares (figura 1, a seguir):

a) adoção de um conhecimento por imitação, com baixo grau de interpretação, por meio de um processo mínimo de comunicação entre os grupos;

b) incorporação de conhecimentos compartilhados, por meio da construção de um entendimento comum acerca da interpretação de determinados fatos ou discursos; implica processos comunicacionais significativos;

c) criação de novos conhecimentos, compartilhando-se "representações metafóricas" do conhecimento incorporado de cada grupo, em um pool sinérgico de saberes e interpretações. A mesma metáfora teria diferentes usos em cada disciplina ou grupo e combinaria elementos do conhecimento incorporado e o conhecimento móbil, permitindo superar algumas das tensões entre práticas, inscrições e conceitos.

A utilização do conceito de "objeto fronteriço", a partir da década de 80 , procuraria dar resposta à questão acerca das possíveis interações heterogêneas entre diferentes atores ou mundos sociais. Ilana Lowith lembra os 
conceitos de "caixas pretas" de Latour (1994) - e de "caixas translúcidas" de Lynch \& Jordan (1992), similares em sua função descritiva ao conceito de "objetos fronteiriços" (boundary object), que tem como uma de suas maiores difusoras a Susan Leigh Star*. Para Star, a comunicação científica se utilizaria desses boundary objects constituídos nos interstícios de universos sociais diferentes, satisfazendo demandas informacionais de cada um deles.

Esses objetos fronteiriços teriam o caráter de objetos referenciais compartilhados que, embora interpretados de diferente maneira em cada grupo ou comunidade, geram um processo de tradução em aberto, mais ou menos difícil ou simplificado, tácito ou consciente e sistemático. Trata-se de fato não só de compatibilização de códigos, mas também de normas e interesses.

Se pensarmos em um objeto musealizado como objeto fronteiriço, poderíamos considerar que estabelece elos entre os produtores originários do objeto e do mundo de sua produção (uma cerâmica utilitária indígena), os museólogos e curadores que o incluem em uma exposição sobre cultura marajoara do Pará (um objeto de valor antropológico, estético ou histórico), e o público do museu que pode olhá-lo das mais diversas maneiras, considerando seu valor decorativo ou vendo nele uma lembrança das férias artesanais de sua terra natal. O museu seria assim um dispositivo informacional que pode reconstruir as malhas que ligam seus objetos museais aos diversos universos culturais de origem e destinação.

Interessa-nos destacar na visão de Star a dupla operação que estes objetos relacionais realizam na interseção das fronteiras de mundos sociais diversos: estabelecer uma relação, mas sem homogeneizar o ponto de vista entre os atores dos diferentes mundos que se cruzam em algum ponto ou direção.

\footnotetext{
* "This is an analytic concept of those scientific objects which both inhabit several intersecting social worlds... and satisfy the informational requeriments of each of them. Boundary objects ar objects that are both plastic enough to adapt to local needs and the constraints of the several parties employing them, yet robust enough to maintain a common identity across sites. They are weakly structures in common use, and become strongly structured in individual-site use. These objects may e abstract or concrete. They have different meanings in different social worls but their structure s common enough to more than one world to make them recognizable, ameans of translation. The creation and management of boundary objects is a key process in developing and maintining coherence across intersecting social worlds" (Star \& Grisemer's ,1989, p.393, cit. em , p.3)
}

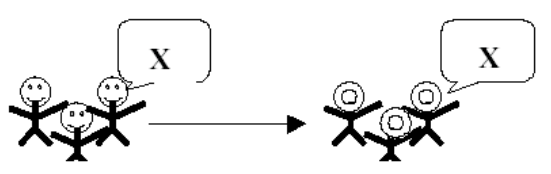

) adoção de informação em forma móbil, mas com baixa interpretação

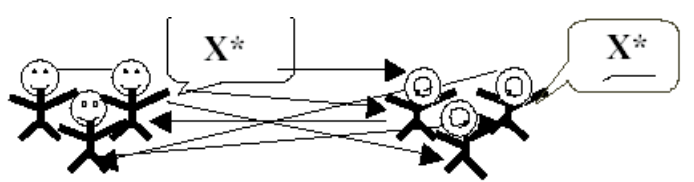
uas práticas

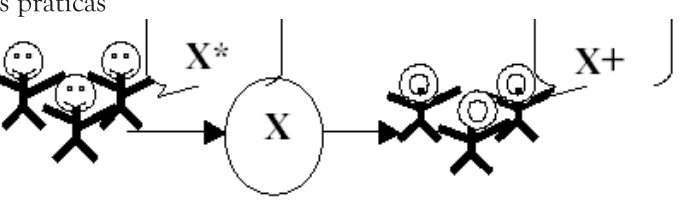

Tipo hipotético de conhecimento metafórico como reinterpretação, que ermite reunir em um processo conhecimento localmente incorporado e móbil e dificado.

de objetos fronteiriços:

1. REPOSITÓRIOS: "pilhas” ordenadas de objetos indexados de uma maneira padronizada, tal como no museu e nas bibliotecas;

2. TIPOS IDEAIS: meios de comunicação e cooperação simbólica, descrições abstratas válidas para todos os domínios, porém adaptáveis a um caso local ou caso singular, tal como um diagrama, por exemplo;

3. COINCIDÊNCIA DAS FRONTEIRAS: objetos que têm os mesmos limites ou fronteiras, mas diferentes conteúdos; o mapa do Brasil, por exemplo, teria sempre os mesmos limites, mas pode ser gerado para representar diferentes conteúdos: clima, acidentes geográficos, hidrografia, densidade populacional e outros.

4. FORMAS PADRONIZADAS: são objetos desenhados como métodos de comunicação comum por grupos dispersos; trata-se de meios, práticas e métodos que podem deslocar-se a grandes distâncias, contêm informação que não muda pelos deslocamentos: uma câmara fotográfica e as fotografias, nas quais não mudam os métodos e práticas de produção dos diferentes produtores, sendo que permite plurais leituras dos produtos a cada uma das comunidades de produção e uso envolvidas. Podemos incluir aqui as classificações bibliográficas e a construção de diferentes índices. 


\section{NOVAS FRONTEIRAS DA REPRESENTAC̣ÃO}

Para Greg Wilson, não se busca nem se obtém consenso pleno. Não seria o conceito de um grupo que sobredeterminaria a concepção de um outro, como forma de chegar a uma interpretação comum e predominante. Para ele, aliás, a comunicação entre grupos culturais diversos, por meio de "objetos fronteiriços", não seria equivalente a uma comunicação metafórica, mas antes um exercício de metonímia:

"Os autores [Star \& Griesemer, J. ] destacam também que um objeto fronteiriço tem mais de um ponto de acesso; um grupo não regula o acesso a este objeto por outro grupo. Logo, tais objetos fronteiriços são mapeamentos de significados muitos a muitos e não mapeamento um a muitos" (Wilson, 2003, p. 6).

O estudo das funções da linguagem seria assim de sumo interesse para nossa compreensão das ações de informação e para a concepção de componentes de recuperação e busca da informação, nos novos cenários. Trata-se de permitir tanto a representação de um critério comum de relevância de comunidades de interlocução, quando dialogam entre si, quanto facilitar a articulação simultânea de julgamentos diferenciados de pertinência, quando temos processos cruzados de comunicação e informação, entre disciplinas e especialidades, entre setores de atividades, entre línguas e narrativas. A metáfora poderia ser um dos instrumentos de descrição e entendimento das ações de informação, gerando uma zona de negociação de significados e uma ponte entre o princípio de autonomia de cada campo científico e o princípio de transversalidade e reinterpretação que requer a geração transdisciplinar de conhecimentos.

\section{Artigo recebido em 18-02-2004 e aceito para publicação em 24-04-2004.}

\section{REFERÊNCIAS}

ALMEIDA FILHO, Naomar. Intersetorialidade, transdiciplinaridade e saúde coletiva: atualizando um debate em aberto. Revista de Administração Pública, v. 34, n. 6, nov./dez. 2000.

BAR-HILLEL, Y. Language and information. London : Addison-Wesley, 1973.

BATES, Marcia J. The cascade of interactions in the digital library interface. Information Processing and Management, v. 38, p. 381-400, 2002. Disponivel em: <http://www.gseis.ucla.edu/faculty/ bates.html>. Acesso em: 11 set. 2003.

CALLON, Michel et al. Réseau et coordination. Paris : Economica, 2003. GEERTZ, C. O saber local. Petrópolis : Vozes, 1998.

GONZÁlEZ DE GOMEZ, M. N. O caráter seletivo das ações de informação. Informare, Rio de Janeiro, v. 5, n .2, p. 7-31, 2000.
Da organização do conhecimento às políticas de informação. Informare, Rio de Janeiro, v. 2, n. 2, p. 58 - 66, 1996.

HABERMAS, J. Direito e democracia: entre facticidade e validade. Rio de Janeiro : Tempo Brasileiro, 1997. p. 65-11. v. 1

Agir comunicativo e razão destranscendentalizada. Rio de Janeiro : Tempo Brasileiro, 2002.

HALL, Stuart, SOVIK, Livia. (Org.). Da diáspora: identidades e mediações culturais. Belo Horizonte : UFMG/UNESCO, 2003.

HJØRLAND, B. Domain analysis in information science. Eleven approaches - traditional as well as innovative. Journal of Documentation, v. 58, n. 4, p. 422-462, 2002. Disponivel em: <http://www.db.dk/ bh/publikationer/Filer/JDOC_2002_>. Acesso em: 02 fev. 2003.

KANFER, A. et al. Modeling distributed knowledge processes in next generation multidisciplinary alliances. In: CONFERENCE OF NEXT GENERATION ENTERPRISES: VIRTUAL ORGANIZATIONS AND MOBILE/PERVASIVE TECHNOLOGIES. Buffalo, NY, 2000. Proceedings... [S. 1. : s. n., 2000?].

LATOUR, B. Ciência em ação: como seguir cientistas e engenheiros sociedade fora. São Paulo : Ed. UNESP, 2000.

LEVY, P. A conexão planetária. Rio de Janeiro : Editora 34, 2001.

\section{3.}

As tecnologias da inteligência. Rio de Janeiro : Editora 34,

LYYTINIEN, K. Two views of information modeling. Information and Management, n. 12, p. 9-19, 1987.

LOWY, Ilana. Fleck e a historiografia recente da pesquisa biomédica. In: PORTOCARRERO, Vera. (Org.). Filosofia, história e sociologia das ciências. Rio de Janeiro : Fiocruz, 1994.

ORRICO, Evelyn Goyannes Dill. Binômio lingüística. Ciência da informação: abordagem teórica para elaboração de metafiltro de recuperação de informação. 2001. Tese (Doutorado em Ciência da Informação) - Universidade Federal do Rio de Janeiro, Rio de Janeiro, 2001

SARACEVIC, Tefko; KANTOR, Paul. A study of information seeking and retrieving. II. Users, questions, and effectiveness. Journal of American Society for Information Science, v. 39, n. 3, p. 177-196, 1988a.

SARACEVIC, Tefko; KANTOR, Paul. A study of information seeking and retrieving. III. Searchers, searches, and overlap. Journal of American Society for Information Science, v. 39, n. 3, p. 197-216, 1988b.

SARACEVIC, Tefko et al. A study of information seeking and retrieving. I. Background and methodology. Journal of American Society for Information Science, v. 39, n. 3, p. 161-176, 1988c.

STAR, S. L.; GRIESEMER, J. R. Institutional ecology, 'translations' and boundary objects: amateurs and professionals in Berkeley's Museum of Vertebrate Zoology, 1907-1939. Social Studies of Science, v. 19, p. 387-420, 1989.

TURNBULL, Don. Augmenting information seeking on the world wide web using collaborative filtering techniques. Disponivel em: <http:// www.gslis.utexas.edu/ donturn/research/augmentis.html>. Acesso em: 10 nov. 2003

VERON, E. Entre la epistemología y la comunicación. Disponivel em: <http://www.ucm.es/info/per3/cic/Cic4ar10.htm>. Acesso em: 12 out. 2003.

WILSON, Greg. Boundary objects and persuasion across discourse communities. Rhetoric Seminar : Los Alamos National Laboratory. <http://www.uiowa.edu/ poroi/MS_Wilson_03.pdf >. Acesso em: dez. 2003.

WITTGENSTEIN, L. Investigações filosóficas. Petrópolis : Vozes, 1996. 